Caivano, O., Leduc, K., \& Talwar, V. (2020). When you think you know: The effectiveness of restrictive mediation on parental awareness of cyberbullying experiences among children and adolescents. Cyberpsychology: Journal of Psychosocial Research on Cyberspace, 14(1), Article 2. https://doi.org/10.5817/CP2020-1-2

\title{
When you Think you Know: The Effectiveness of Restrictive Mediation on Parental Awareness of Cyberbullying Experiences Among Children and Adolescents
}

\author{
Oksana Caivano, Karissa Leduc, \& Victoria Talwar \\ McGill University, Montreal, Quebec, Canada
}

\begin{abstract}
The current study examined parental awareness of their child's cyberbullying experiences in relation to the implementation of restrictive mediation strategies (e.g., interaction and technical restrictions) among children in elementary school and adolescents in high school. Canadian parent-child dyads $(N=102)$ completed a survey where parents reported their perceptions of their child or adolescent's involvement in cyber aggression, cyber victimization, and witnessing cyber aggression, while children and adolescents (ages 8-16) reported their own experiences. Mean difference scores were calculated to examine parental awareness. The results showed that parents of children in elementary school underestimated their participation in cyber aggression, whereas parents of adolescents in high school overestimated their participation in cyber aggression. In addition, parents of adolescents who did not use restrictive mediation underestimated the extent to which their adolescent witnessed cyber aggression. Overall, this study highlights the importance of parenting practices and parental knowledge of negative online behaviour across childhood and adolescence.
\end{abstract}

Keywords: Parental awareness; parental mediation; restrictive mediation; cyberbullying; victimization; bystander

\section{Introduction}

Research has shown that parents often underestimate their child's experience as a perpetrator or victim of cyberbullying (e.g., Byrne et al., 2014; Livingstone \& Bober, 2004). In hopes of reducing negative online behaviour, some parents have begun setting online rules for their child (Monks et al., 2016). Unfortunately, parents who are unfamiliar with technology often have difficulty monitoring their child's behaviour online, as they struggle and lack confidence when using digital media (Wang et al., 2005). This is related to the fact that today's youth are exposed to technology earlier than their parents were, giving them more time to become experts at using it (Wong, 2010). This gap in skills makes it difficult for parents to teach and guide their child on how to identify threating and reliable information online (e.g., a photoshopped picture; Ahmad et al., 2019; Livingstone \& Bober, 2004). Although research has shown that digital media usage increases with age, it is now reported to be accessed by elementary school children (Mascheroni \& Cuman, 2014). In Canada, 25\% of children admit to engaging in cyberbullying behaviour, one in three are victimized online (PREVNet, 2014), and one in five witness cyberbullying (Ipsos, 2013). Therefore, it is especially important to further explore this trend and understand how parental strategies, such as parental supervision in the form of online rules and restrictions (e.g., technical or website restrictions), can affect parental awareness of their child's online behaviour. Parental awareness is the first step towards intervention for children and adolescents who are cyber aggressors or cyber victims and prevention for those who witness cyberbullying. Thus far, there is limited research that has examined parents' online restrictions and parental awareness of their child's online behaviour, especially in relation to cyberbullying exposure and how this changes with age. As such, the aim of the current study was to examine differences across age in parental awareness of children and adolescents' experiences with cyberbullying in relation to the implementation of restrictive mediation. 


\section{Parents' Awareness of Their Child's Online Behaviours}

Across the globe, parents are inaccurate when reporting how their child spends their time online (e.g., Cho \& Cheon, 2005). Parents overestimate how often their child uses the Internet for academic purposes (Katz et al., 2015) and underestimate their unsafe Internet behaviour such as viewing age-inappropriate websites (Cho \& Cheon, 2005). Furthermore, Symons et al. (2016) found that both parents underestimated their adolescent's involvement in negative online activity (e.g., cyberbullying, adding strangers to social networking websites). Together, these studies suggest that parents do not realize the extent to which their child engages in risky online behaviour.

Parents also lack knowledge regarding their child's experiences specific to cyberbullying. Several studies have demonstrated that parents are not aware that their child has either cyberbullied others or has been a victim of cyberbullying (e.g., Byrne et al., 2014; Livingstone \& Bober, 2004). In the United States, only one in three parents of children and adolescents between the ages of 10 and $16 \mathrm{knew}$ that their child was bullying others online (Byrne et al., 2014). However, it should be noted that in this study reports were considered accurate if the child and parent both stated that the child engaged in cyberbullying at least once; it did not take into account the discrepancy between the child's report and parent's report. Therefore, while the parent may have been aware of an occurrence of cyberbullying, it is possible that it was a more problematic behaviour than they realized. In the UK, $33 \%$ of children and adolescents between the ages of 9 and 19 disclosed being cyberbullied, while only $4 \%$ of parents were aware that their child was victimized (Livingstone \& Bober, 2004). This lack of awareness is problematic because it hinders parents' ability to support their child in times of distress.

Overall, these findings suggest that parents lack knowledge about their child's involvement in cyberbullying. Ang et al. (2012) demonstrated that parental awareness of online activity is important for reducing risky online behaviour. More specifically, adolescents with low levels of loneliness were less likely to engage in problematic online behaviour when their parents were aware of their online behaviour. Such findings suggest that parents' awareness is important for reducing problematic behaviour online, including cyberbullying. In order to understand how parents can become more aware of their child's cyberbullying experiences, it is important to understand what types of parenting methods, such as mediation strategies of online activities, should be implemented. Therefore, research that further explores what parenting methods can increase parental awareness of online behaviour is needed to prevent negative online interactions and experiences.

\section{Television Versus Online Restrictive Mediation}

A large majority of parents claim to set restrictive rules for their child's Internet usage (McQuade et al., 2009). This parental strategy is considered a form of parental mediation, specifically, restrictive mediation. Parental mediation theory was developed in relation to television media and is associated with parenting strategies used on children in efforts to reduce the negative effects of media (Clark, 2011). Restrictive mediation involves enforcing rules and restrictions about viewing and content, active mediation involves having a discussion about content, and finally, and co-viewing involves watching the child to be aware of the content they are viewing (Bybee et al., 1982; Dorr et al., 1989; Weintraub Austin, 1993).

Research has yielded mixed results about using restrictive mediation to protect from harmful television content (e.g., Nathanson, 1999, 2002; Van den Bulck \& Van den Berg, 2000). Nathanson (2002) found that adolescents had negative views about their parents' restrictions, and they were more likely to find alternate ways to watch the restricted content. However, restrictive mediation has been found to have more positive outcomes compared to co-viewing and similar outcomes to active mediation (Nathanson, 1999). It should also be noted that restrictive mediation and children's aggressive behaviour follows a curvilinear relationship. While moderate levels of restrictive mediation were related to less aggressive behaviour in children, those whose access to content was too restricted or not restricted enough, were more aggressive (Nathanson, 1999). Nonetheless, restrictive mediation has been shown to reduce overall media use (Van den Bulck \& Van den Berg, 2000) suggesting that when used appropriately, it can be an effective parenting strategy compared to active and co-viewing forms of mediation.

Similar to television restrictive mediation, parents might engage in online restrictive mediation with fear as a motive (Mascheroni, 2014; Zaman et al., 2016) and this stems from parents wanting to protect their child from harmful content (van Kruistum \& van Steensel, 2017). Other research has shown that parents believed their child had too much access to their devices, spent too much time using them, and were in need of a balance between online and offline activities 
(Daneels \& Vanwynsberghe, 2017; van Kruistum \& van Steensel, 2017). In other cases, parents chose not to use restrictive mediation because they were certain that their child was less likely to be influenced by media and had the ability to recognize negative content compared to other children (Nathanson et al., 2002). In fact, many parents reported choosing not to set restrictions and gave their child more freedom instead (van Kruistum \& van Steensel, 2017).

In the realm of digital media, parents have had to learn to adapt restrictive strategies to protect their child from the influences of online content such as cyberbullying. Livingstone and Helsper (2008) sought to examine differences between television mediation practices and online mediation practices. Using factor analysis, the authors found two types of restrictive mediation practices: interaction restrictions whereby social interactions such as emails and messaging were not allowed and technical restrictions whereby a software was installed to block or filter activity. Interestingly, they found that active and co-viewing fell into a combined category called active co-use. In addition to having discussions with the child and being with or nearby the child when they went online, active co-use included rules about time spent online, doing online quizzes, and making purchases. The authors argued that although active co-use involved setting rules, these types of rules were accompanied by conversations or a parent being present, hence their fit into the active co-use category. Lastly, physically checking sites and messages had its own category called monitoring. This suggests that television and online mediation practices might not be directly comparable. As such, researchers have begun examining online restrictive mediation in relation to children's negative online experiences (e.g., Chng et al., 2014; Ho et al., 2017; Wright, 2017), given the increase in technology usage among youth. However, there is limited research on restrictive mediation and parental awareness of their child's cyberbullying experiences. It is expected that by setting restrictive rules, parents will be aware of their child's online behaviour, as they would be aware of what their child is not allowed to do online.

\section{Restrictive Mediation and Cyberbullying}

Restrictive mediation is a fairly common strategy implemented by parents, although as children get older, parents tend to give their child more freedom and enforce fewer rules (Nikken \& Jansz, 2014; Spears et al., 2005; Symons et al., 2017). Nowadays, given how widespread digital media is, there can be several devices in a home, in addition to personal phones, which children and adolescents have with them almost at all times, sometimes while they are away from their parents (e.g., in their room at night, while at school; Mascheroni \& Cuman, 2014). Therefore, it is especially important that parents are attentive to negative behaviour their child may exhibit or negative experiences they may encounter online.

There have been several studies that have examined the implementation of online rules in relation to children's negative online experiences (e.g., Chang et al., 2015; Spears et al., 2005; Wright, 2016), however, research has yielded mixed findings. Spears and colleagues (2005) found that restrictive mediation reduced negative online activities such as visiting inappropriate sites, meeting strangers, and revealing personal information. The authors stated that children were less likely to engage in these behaviours because the rules decreased how often they were online. However, they also mentioned that rules were less effective with age, where older children were more likely to disobey the rules. These results have been found in relation to cyberbullying as well. Ho et al. (2017) found that restrictive mediation was more successful for reducing cyber aggression in younger children, as older children were more mature and less responsive to restrictive mediation. Conversely, Wright (2017) found that restrictive mediation reduced cyber aggression one year later in adolescents. It should be noted that Wright used adolescents' perceptions of their parents' mediation practices and they may not have been fully aware of what their parents were doing (e.g., installing a monitoring software). Furthermore, in both $\mathrm{Ho}$ et al. and Wright's studies, restrictive mediation included time restrictions, which according to Livingstone and Helsper (2008), was an active co-use strategy. Chang et al. (2015) found that higher levels of restrictive mediation reduced both online aggression and victimization. In this study, restrictive mediation was measured with a questionnaire by Livingstone et al. (2011), similar to Livingstone and Helsper (2008), although technical restrictions were included as a separate category, but were not associated with cyberbullying experiences.

Concerning victimization, Mesch (2009) found that restrictive mediation in the form of monitoring websites was linked to a decrease in cyber victimization. In this study, parental monitoring of online accounts was included as restrictive mediation, which does not qualify as restrictive (Livingstone \& Helsper, 2008). Conversely, Wright (2016) found that restrictive mediation increased cyber victimization, arguing that restrictive mediation was not enough to prevent victimization. Sometimes, children are afraid to tell their parent about being cyberbullied because they do not want more restrictions (Navarro et al., 2013). However, it should be noted again that in Wright's study adolescents' perceptions of their parents' mediation style were used, which may not give us an accurate picture of their parents' actual strategies. These mixed findings might be explained by the lack of consistent measurement of online restrictive mediation. Future 
research on online restrictive mediation needs to be defined and measured consistently to fully understand the relationship between restrictive mediation and cyberbullying.

Less research has examined restrictive mediation in relation to parental awareness of their child's cyberbullying experiences. One study in the Netherlands found that parents who set rules about what children can and cannot do online and rules about time spent online still underestimated the extent to which their child engaged in cyberbullying or was a victim of cyberbullying (Dehue et al., 2008). The results showed that $17.3 \%$ of elementary and high school students admitted to cyberbullying others, whereas only $4.8 \%$ of parents knew about this behaviour. Regarding being cyberbullied, the authors reported that $22.9 \%$ of children confessed to being cyberbullied, while only $11.8 \%$ of parents were aware of this. Another study found that even with setting rules, limiting time, and talking about cyberbullying, parents still underestimated their child's engagement in cyberbullying. However, it should be taken into consideration that these rules were a mix of restrictive and active mediation practices (Barlett \& Fenell, 2018). Overall, as parents, being unaware of cyberbullying experiences does not give them the opportunity to educate their child on how to appropriately interact with others online and provide support for them in navigating victimization.

Notably, there is a lack of research examining restrictive mediation and parental awareness of cyberbullying experiences. Although Dehue and colleagues' (2008) study focused on rules more generally as opposed to restrictive mediation, and Barlett and Fenell (2018) focused on a mix of restrictive and active mediation practices, research has yet to focus on restrictive mediation alone and parental awareness. Furthermore, while parental awareness of cyber aggression (Barlett \& Fenell, 2018; Dehue et al., 2008) and victimization (Dehue et al., 2008) has been examined, there is limited evidence that exists on restrictive mediation and parental awareness for younger compared to older children. This is especially true for parental knowledge of their child's online bystander behaviour, in addition to cyber aggression and victimization. Cyberbullying is a prevalent issue in both elementary and high school children (Smith et al., 2008), with some research suggesting that cyberbullying in elementary school may be even more common than it is in high school, which parents are not aware of (Dehue et al., 2008; Monks et al., 2016). Furthermore, our experience with the Internet has changed prominently in the last 10 years, as access to the Internet is more widespread and social media has become increasingly popular (Mascheroni \& Cuman, 2014). Notably, Ang (2015) also argued that children and adolescents have different needs when it comes to parental mediation. Given these differences across age, it is important to understand how to tailor restrictive mediation strategies to younger and older children. As such, more research on changes across childhood and adolescence in this area is needed. Depending on the type of cyberbullying involvement (i.e., the bully, victim or witness), different parenting approaches may be more successful for different age groups to increase parental awareness of cyberbullying and the type of support they choose to put forth for their child.

\section{The Current Study}

The current study investigated restrictive mediation and parental awareness of their child's cyberbullying experiences (as a perpetrator, victim or bystander) by examining parents' perceptions of their child's experiences and their child's reported experiences. The transition to high school has been associated with parental concern of bullying (Zeedyk et al., 2003), therefore, age differences were expected and examined by comparing children in elementary school (approximately 8-12 years old) to adolescents in high school (approximately 13-16 years old).

According to Dehue et al. (2008), parents who set rules for their child and adolescent underestimated their engagement in cyber aggression, but no age differences were examined. However, the current study examined age patterns and we expected differences. Based upon Dehue et al. (2008), and Barlett and Fennel (2018), it was expected that parents of children in elementary school who used restrictive mediation would underestimate cyber aggression and parents of adolescents in high school who used restrictive mediation would accurately report their involvement in cyber aggression (Hypothesis 1). These differences were expected because parents worry about cyberbullying for adolescents and according to them, cyberbullying incidents are most prevalent during the teenage years (Anderson, 2018; Monks et al., 2016). However, parents fail to realize that cyberbullying is also an issue that has reached younger children (Monks et al., 2016). Consequently, we expected that parents would more accurately report adolescents' engagement in cyber aggression while parents of elementary age children would underestimate cyber aggression.

Next, similar to the findings of Dehue et al. (2008), we expected that with the implementation of restrictive mediation, parents would underestimate their child and adolescent's victimization experience (Hypothesis 2). It was expected that parents would be unaware about their child's victimization experience because children may not be disclosing that they were victimized out of fear (Belsey, 2019; Navarro et al., 2013). If children experienced victimization, they would expect 
that telling their parents might lead to the implementation of more restrictions, as a result of parents trying to protect them (Cerna et al., 2016; Navarro et al., 2013).

Finally, it was expected that without restrictive mediation, parents would underestimate their adolescent's exposure to cyberbullying as a bystander (Hypothesis 3). Previous research with television and online mediation showed that parents do not implement restrictive mediation strategies because they believe they do not need to. Parents believe that their child has the ability to detect negative content when they see it (Nathanson et al., 2002), giving their child freedom to "do their own thing" (van Kruistum \& van Steensel, 2017, p. 13). We expected that parents of adolescents who do not use restrictive mediation would likely think that their child would further avoid this type of negative content after viewing it, leading to inaccurate reports of bystander experiences.

\section{Method}

\section{Sample and Procedure}

The university's Research Ethics Board approved this study. Participants were recruited from a research participant database and newspaper advertising. Parents who agreed to participate in the study with their child were invited to the research lab located on the university's campus. The data was collected throughout 2017 and early 2018.

One hundred two Canadian parent-child dyads participated in the study. Children and adolescents were between 8 and 16 years old $(M=11.59$ years, $S D=2.25$ years). Sixty-six child participants were children in elementary school $(48.5 \%$ male) and 36 were adolescents in high school (47.2\% male). Eighty-one percent of children and adolescents reported using social media, $69 \%$ on a weekly basis. Seventy-six percent reported using gaming websites, $36 \%$ on a weekly basis. The parent who accompanied their child to the appointment participated in the study as well. Eighty-six percent were mothers and $14 \%$ were fathers.

Families also reported their primary ethnicity (Table 1) and language. The primary reported ethnic groups were Canadian, European, and Jewish. Almost seventy-six percent reported English as their first language, 13.6\% French, 1.9\% Greek, Russia, and Spanish, and 1\% Cantonese, Czech, Farsi, Italian, and Twi.

\begin{tabular}{lcc}
\multicolumn{3}{c}{ Table 1. Participant Ethnic/Cultural Background. } \\
\hline Ethnic/cultural group & Frequency & Percent (\%) \\
\hline Canadian & 56 & 54.9 \\
European & 20 & 19.6 \\
Jewish & 9 & 8.8 \\
Asian & 5 & 4.8 \\
Caucasian & 3 & 2.9 \\
Latin & 3 & 2.9 \\
Middle Eastern & 2 & 1.9 \\
Caribbean & 2 & 1.9 \\
Central American & 1 & 1 \\
Not reported & 1 & 1 \\
\hline
\end{tabular}

Parents provided consent for their child and themselves to participate in the study. Parents filled out the survey while a research assistant took the child into a separate room. Before completing the survey, the participants provided verbal assent.

\section{Materials}

Demographics. Parents completed a demographics questionnaire that asked them about their ethnic/cultural background and primary language spoken to which they answered open-endedly. 
Parent survey. To assess parents' use of restrictive mediation strategies, they were asked whether they set rules for their child's Internet activities (yes/no item). For those that replied yes, parents were asked a follow-up open-ended question about the nature of the rules (If so, what are the rules that you have set")? To verify that parents did indeed engage in restrictive mediation and not other online rules that were not restrictive (e.g., parental monitoring), we referred to Livingstone and Helsper's (2008) list of online restrictive practices (interaction and technical restrictions, p. 588), as a guide for our coding scheme (see Table 2). In both interaction and technical restrictions, Livingstone and Helsper's (2008) restrictive practices included banning or limiting emails, chatrooms and instant messaging. In the current study, we also included more current forms of social media that go beyond just messaging and also contain picture sharing features (e.g., Instagram). Furthermore, we added gaming websites to our definition of technical restrictions. After verifying that the restrictions were either interaction or technical restrictions, our final variable was dichotomous to reflect if parents set any type of restrictive mediation (coded as yes/no). The coding of any type of restrictive mediation was verified with a second rater who coded $20 \%$ of the data $(\kappa=1)$. This data was randomly selected using the random function (i.e., RAND) in Excel and the first 21 responses were coded by the second rater. Sample items of restrictive mediation rules (interaction and technical restrictions) and non-restrictive rules are also presented in Table 2.

Table 2. Coding Scheme for Restrictive Mediation.

\begin{tabular}{|c|c|c|}
\hline $\begin{array}{l}\text { Type of restrictive } \\
\text { mediation }\end{array}$ & Definition & Sample items from parents \\
\hline Interaction & $\begin{array}{l}\text { Parent bans certain content (e.g., social } \\
\text { media, gaming websites, inappropriate } \\
\text { websites for downloading) and/or limits } \\
\text { the child to using chosen } \\
\text { activities/websites (e.g., enchanted } \\
\text { learning) }\end{array}$ & $\begin{array}{l}\text { Only trusted websites/apps approved by me } \\
\text { [parent], no downloading anything we have } \\
\text { not seen, and no profiles. } \\
\text { [Child] cannot go on violent sites, and no } \\
\text { social media. }\end{array}$ \\
\hline Technical & $\begin{array}{l}\text { Parent uses filtering or monitoring } \\
\text { software to physically block certain } \\
\text { content (e.g., social media, games, } \\
\text { inappropriate websites) }\end{array}$ & $\begin{array}{l}\text { Parental controls on [child's] account, can } \\
\text { work during the week with parent's } \\
\text { permission; videogames and video/movies } \\
\text { only on weekends. } \\
\text { We have a set of parental control on [child's] } \\
\text { computer and iPads. It limits what [child] can } \\
\text { search. }\end{array}$ \\
\hline $\begin{array}{l}\text { No restrictive } \\
\text { mediation }\end{array}$ & $\begin{array}{l}\text { Parent uses no rules or rules do not fit } \\
\text { interaction or technical restrictive } \\
\text { mediation }\end{array}$ & $\begin{array}{l}\text { Not more than } 30 \text { minutes online. } \\
\text { The Internet is a privilege; you earn time. } \\
\text { Misbehaviour means no Internet. I don't } \\
\text { necessarily watch over [my child] but I hear } \\
\text { at all times. }\end{array}$ \\
\hline
\end{tabular}

Cyber-aggression, cyber-victimization, and cyber-witness scale (based on Menesini, Nocentini and Calussi, 2011). A modified version of Menesini and colleagues' (2011) Cyber-Aggression (CA Child Males $\alpha=.86$; CA Child Females $\alpha=$ .67 ) and Cyber-Victimization Scale (CV Child Males $\alpha=.87$; CV Child Females $\alpha=.72$ ) was given to child and adult participants. The same scale, but with questions framed from a witness perspective (CW Child Males $\alpha=.90 ; \mathrm{CW}$ Child Females $\alpha=.82$ ) was also administered (CA Child, CV Child, CW Child $\alpha=.85$ ). Child participants were given the option of completing the questionnaire independently or with the researcher. Children completed three nine-item scales on their experience with cyber aggression (e.g., "I sent insults on social media"), cyber victimization (e.g., "I received rude comments on a website"), and witnessing cyber aggression (e.g., "I saw someone post unpleasant pictures on Facebook"). Participants were asked to reflect on these experiences in the last two months, and responses were scored on a scale from 0 (never) to 4 (several times a week) for a possible total of 36 points per scale. Parents completed the same questionnaire (CA Parent $\alpha=.60 ;$ CV Parent $\alpha=.67$; CW Parent $\alpha=.90$; CA Parent, CV Parent, CW Parent $\alpha=.91$ ) but responded from the perspective of their child (i.e., "In the last two months, how many times do you think your child sent/received/seen XXX?"). 


\section{Results}

\section{Analysis Plan}

First, we conducted chi square analyses to examine age differences in the implementation of parental mediation and the two specific restrictive mediation practices: interaction and technical restrictions. Second, across both school groups, we reported the child and parent-reported mean difference scores on each cyber subscale. Third, to investigate restrictive mediation and parental awareness of their child's cyberbullying experiences, we conducted a two-way MANOVA. Followup $t$-tests were then used to locate the significant differences.

\section{Descriptive Statistics}

In total, $83.3 \%$ of parents used any type of restrictive mediation. In the current study's sample, $80.6 \%$ of parents with adolescents in high school and $84.8 \%$ of parents with children in elementary school used restrictive mediation and this difference was not significant ( $p=.687$; see Table 3 ). Parents who used any type of restrictive mediation were classified into interaction or technical restrictions and there was no overlap between the parents who used interaction restrictions and those who used technical restrictions. We found that of the parents who used restrictive mediation, a large majority used interaction restrictions ( $96 \%$ overall). Of those who used interaction restrictions, $94 \%$ were parents of an elementary school child and $6 \%$ were parents of a high school adolescent. The number of parents who used technical restrictions was very small and not analysed further. Thus, these categories were combined as restrictive mediation in all subsequent analyses. There were no differences between elementary and high school participants in the implementation of interaction versus technical restrictions $(p=.247)$.

Table 3. Descriptive Statistics of Restrictive Mediation by School Category.

\begin{tabular}{lcccccc}
\hline \multirow{2}{*}{ School category } & \multicolumn{2}{c}{ Restrictive mediation } & & \multicolumn{2}{c}{ No restrictive mediation } \\
\cline { 2 - 3 } \cline { 5 - 6 } & $n$ & $\%$ & & $n$ & $\%$ \\
\hline Elementary school & 56 & 84.8 & & 10 & 15.2 \\
High school & 29 & 80.6 & & 7 & 19.4 \\
\hline
\end{tabular}

\section{Parental Awareness of Cyberbullying Experiences}

To examine parental awareness of their child's cyberbullying experiences, mean difference scores were used for all analyses (see Figure 1). Mean difference scores were calculated on the overall score per cyber subscale (CyberAggression, Cyber-Victimization, and Cyber-Witness), subtracting the child's overall score on a subscale from the parent's score on the same subscale (see Table 4). The three mean difference scores per cyber subscale were used in the subsequent analyses. Positive scores were indicative of parents overestimating their child's cyberbullying experiences, the largest difference being 36. Negative scores were indicative of parents underestimating their child's cyberbullying experiences, the largest difference being -36 . 


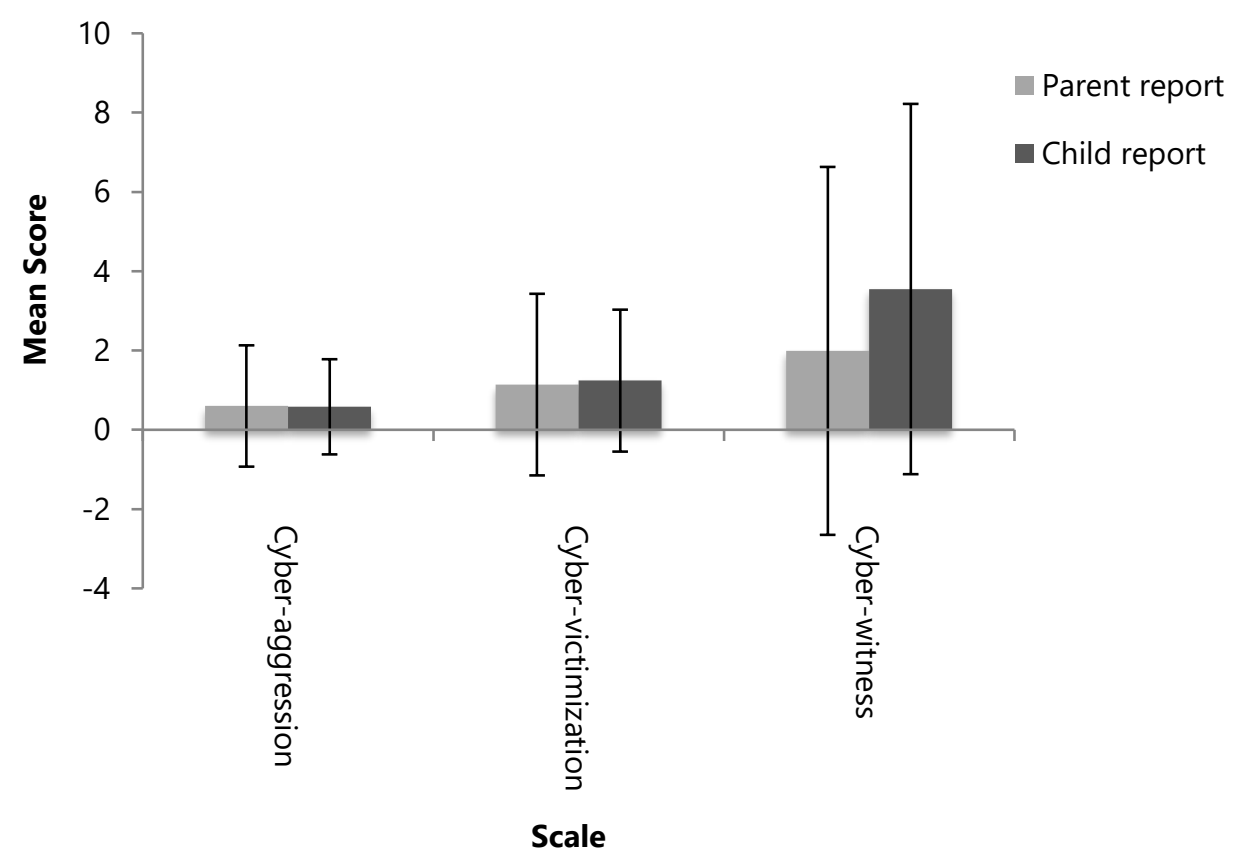

Figure 1. Parent perception of their child's cyberbullying experiences and their child's actual experiences.

Table 4. Parent and Child Mean Scores (SD) and Mean Difference Scores Per Scale.

\begin{tabular}{lccc}
\hline Cyber scale & Parent report M (SD) & Child report M (SD) & Mean difference \\
\hline Aggression & $0.6(1.55)$ & $0.58(1.21)$ & 0.02 \\
Victimization & $1.14(2.52)$ & $1.24(1.80)$ & -0.1 \\
Witness & $1.99(4.69)$ & $3.55(4.67)$ & -1.56 \\
\hline
\end{tabular}

Mean difference scores per cyber subscale and across school category for all participants are reported in Table 5.

Table 5. Mean Difference Scores Per Scale Across School Category.

\begin{tabular}{lcc}
\hline Cyber scale & Elementary school mean difference & High school mean difference \\
\hline Aggression & -0.2 & 0.42 \\
Victimization & -0.47 & 0.58 \\
Witness & -1.97 & -0.83 \\
\hline
\end{tabular}

A two-way MANOVA was used to examine parental awareness of their child's experiences with cyber aggression, cyber victimization, and witnessing cyber aggression as a function of the implementation of online restrictive rules as a measure of any type of restrictive mediation (yes/no) and school category (elementary school/high school). Multivariate outliers were tested using Mahalanobis distance. Two outliers were found, but were kept in the analyses, as they did not change the results. Since we did not have equal samples sizes in each cell of our design, Levene's Test of Equality of Error Variances and Box's Test of Quality of Covariance Matrices (Box's M) were used to test for equality of variance. Levene's Test was not significant for each scale (aggression, $p=.096$; victimization, $p=.429$; witnessing, $p=.902$ ). In addition, Box's $M$ was not significant, $p=.62$. Overall, this indicated that our MANOVA was robust and statistical assumptions were met.

The MANOVA results showed no main effect of restrictive mediation, Wilk's $\Lambda=.942, F(3,94)=1.945, p=.132, \eta_{p}{ }^{2}=$ .058. However, there was a significant main effect of school category, Wilk's $\Lambda=.917, F(3,94)=2.848, p=.042, \eta_{p}^{2}=$ .083. Specifically, the results demonstrate that parents with a child in elementary school underestimated their 
engagement in cyber aggression, whereas parents with an adolescent in high school overestimated their engagement in cyber aggression (see Figure 2).

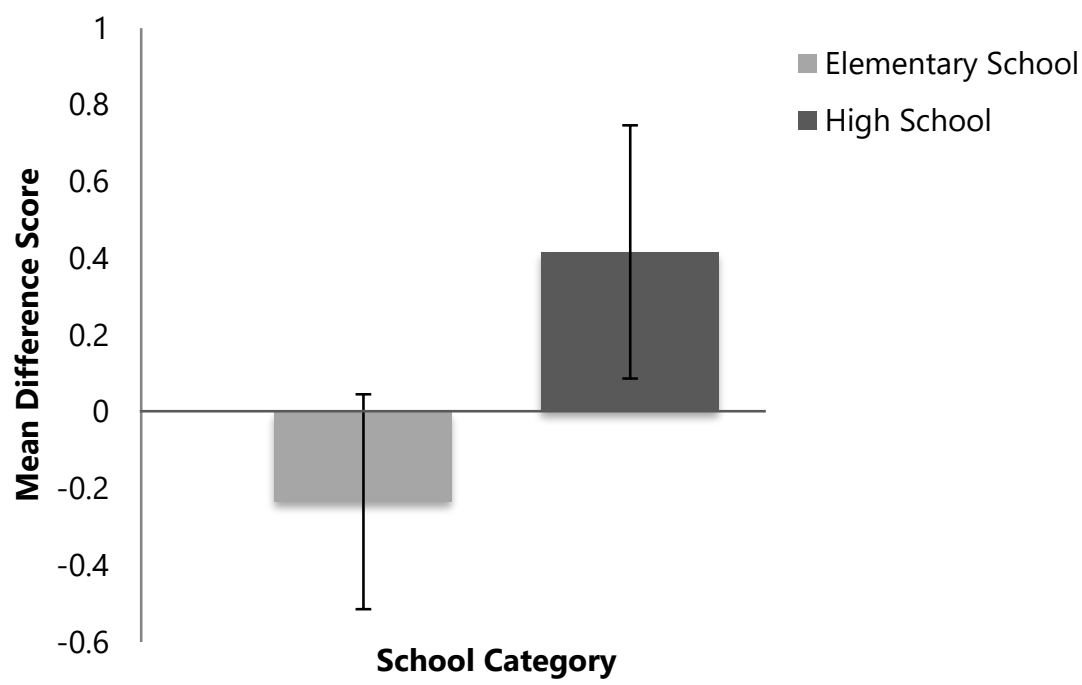

Figure 2. Parental awareness of their child's experience with cyber aggression as a function of school category.

In addition, a significant interaction was found between school category and restrictive mediation, Wilk's $\wedge=.904, F(3$, $94)=3.321, p=.023, \eta_{p}^{2}=.096$. As a follow up, independent samples $t$-tests were conducted for each school category. For children in elementary school, there were no significant differences found on all three scales, Cyber-Aggression scale, $t(64)=-1.664, p=.101$, Cyber-Victimization scale, $t(64)=0.096, p=.924$, Cyber-Witness scale, $t(64)=-0.52, p=.605$. For adolescents in high school, no differences were found on the Cyber-Aggression, $t(34)=0.253, p=.802$, and CyberVictimization scale, $t(34)=-1.001, p=.324$. However, there were significant differences on the Cyber-Witness scale, $t(34)$ $=-2.406, p=.022$. This result suggests that parents who did not use restrictive mediation $(M=-5.71, S E=2.04)$ for their adolescent in high school underestimated how often their adolescent was a bystander to cyberbullying compared to parents who did use restrictive mediation ( $M=0.34, S E=1.13$; see Figure 3$)$.

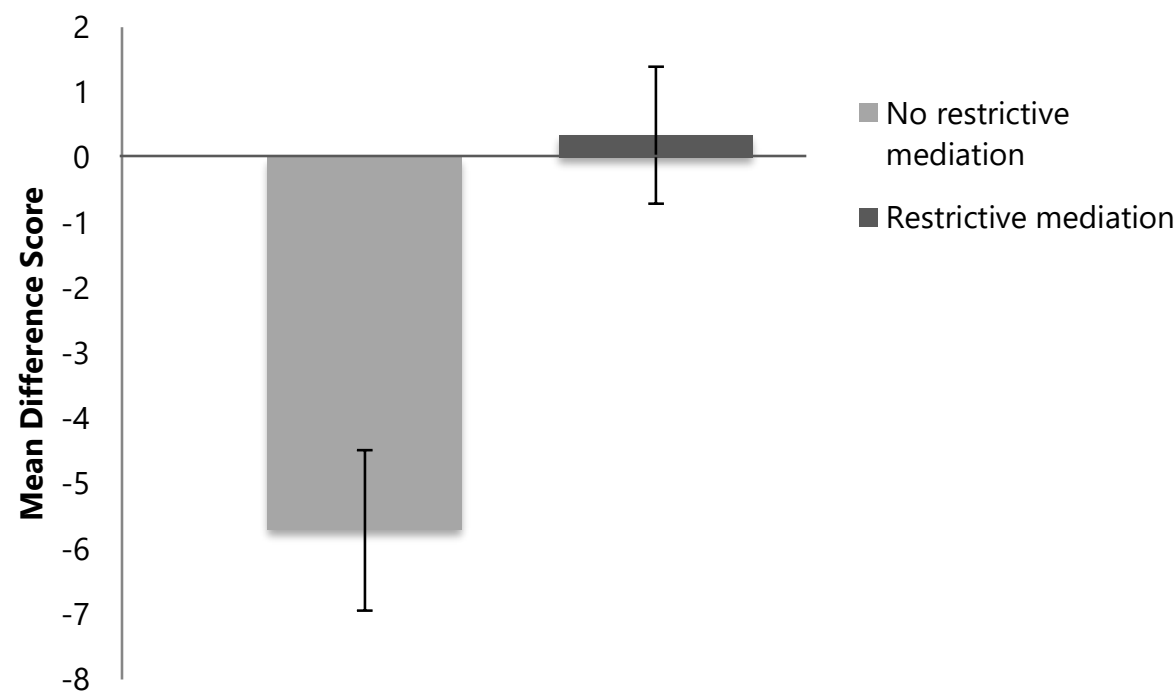

Restrictive Mediation

Figure 3. Parental awareness of their child's experience witnessing cyber aggression as a function of restrictive mediation.

\section{Discussion}

The purpose of the current study was to examine children and adolescents' cyberbullying experiences and the extent to which restrictive mediation made parents more aware of these experiences. This study was the first to examine parental perception and awareness of cyberbullying in relation to school category. Overall, the results suggest that parents are not fully aware of the extent of their child and adolescent's cyberbullying involvement, similar to what is reported in previous literature (Barlett \& Fennel, 2018; Dehue et al., 2008). Restrictive mediation in the form of interaction and 
technical restrictions was found to be most effective for parents' awareness of adolescents' experiences witnessing cyberbullying.

Previous research has shown that parents who set online rules underestimated their child and adolescent's cyber aggression behaviour (Barlett \& Fennel, 2018; Dehue et al., 2008). The current study found that restrictive mediation was not a factor related to parental awareness of their child's engagement in cyber aggression. Instead, parents of children in elementary school underestimated the extent to which their child was involved in being an aggressor of cyberbullying. Parents of adolescents in high school, however, overestimated their engagement in cyber aggression. Together, these results only partially supported our first hypothesis. One study found that children's perceptions of their peers' approval of risky online behaviour reduced the effectiveness of restrictive mediation in preventing children ages 10-16 from engaging in that behaviour (Sasson \& Mesch, 2014). Therefore, if parents believe that cyberbullying is a common problem among adolescents (Monks et al., 2016), they might have believed that their adolescent's peers were engaging in online aggression and this might have influenced their adolescent to engage in cyber aggression themselves. This might have led parents to overestimate cyber aggression for adolescents. However, parents do not realize that cyberbullying is also a concern for younger children (Monks et al., 2016). This may explain why parents underestimated engagement in cyber aggression among children. Cyberbullying is a growing problem and is a prevalent issue among young children as well (Dehue et al., 2008; Smith et al., 2008). The current study suggests that parents may not realize the extent to which cyberbullying has reached elementary-age children, leading to inaccurate perceptions of their child's cyber aggression. Together, this might suggest that restrictive mediation was outweighed by parents' perceptions of cyberbullying as a phenomenon. For parents of elementary school children especially, where they underestimated their child's cyber aggression, they may unknowingly be missing the opportunity to discuss the repercussions for the aggressor and the victim.

With regard to victimization, there was no effect of school category or restrictive mediation on parental awareness of their child's cyberbullying experience. Contrary to our second hypothesis, restrictive mediation did not make parents more aware of their child's experience as a victim. One study demonstrated that setting restrictions was not effective for cyber victims to talk about their experience with their parents (Cerna et al., 2016). The authors argued that although victims did not confide in their parents, restrictions alone did demonstrate an interest in their child's online activities. Restrictive mediation was positively correlated with parental knowledge of online activities, which included cyberbullying victimization, but children were still not comfortable disclosing to parents. The current study, however, suggests that both parents who used restrictive mediation and those who did not were relatively aware of their child's experience with cyber victimization. It has been previously suggested that while parents are more aware of cyber victimization than other online behaviours, they may still underestimate it (Symons et al., 2016). The current study's findings suggest that parents may be less likely to underestimate cyber victimization. This may be because of an overall parental awareness that online threats are an increasing issue (Ahmad et al., 2019). Recent research has shown that parents of children and adolescents are beginning to inform themselves about cyber safety and protecting their child, and this might include setting rules, discussing with other parents or attending talks (Ahmad et al., 2019). Therefore, parents may be trying to do more to be aware of their child's victimization experiences. This may include setting restrictions or using alternative strategies, which suggests that even without rules, parents can find ways be aware of victimization. Parents should be encouraging their child to be vocal about their experiences with online victimization so they can provide guidance to their child on how to handle and overcome it.

Next, school category played a role in how the implementation of restrictive mediation strategies affected parental awareness of their child's exposure to cyberbullying. Confirming our third hypothesis, parents of adolescents in high school who did not use restrictive mediation underestimated their adolescent's experience being a witness to cyberbullying. Parents of adolescents who did use restrictive mediation accurately reported their experience as a bystander. While the current study showed that restrictive mediation was particularly effective for knowledge about witnessing cyberbullying in high school adolescents, other studies suggest that restrictive mediation may pose too many limits for adolescents and that more active and cooperative strategies are better suited (Lee, 2012; Sasson \& Mesch, 2014). However, more research is needed to understand how technical versus interaction restrictions may be more effective for adolescents' experiences with cyberbullying and parental awareness. Other research states that parents grant their child freedom online if they believe that their child does not need to have their access restricted (van Kruistum \& van Steensel, 2017). Furthermore, research by Nathanson et al. (2002) showed that parents who do not engage in parental mediation chose not to do so because they think their child is less likely to be influenced by negative media compared to other children. In the current study, it may be that parents who did not use restrictive mediation for adolescent thought it was unnecessary, they did not perceive any online threats, and wanted to give their child more autonomy online (van Kruistum \& van Steensel, 2017). It is possible that parents believed their adolescent was mature 
enough to know to avoid negative online content, whether that included avoiding certain platforms or people that engaged in cyberbullying and thus, would be less likely to witness cyberbullying. For children, restrictive mediation did not make parents any more aware of their child's bystander experience. Regardless of the implementation of restrictive mediation, parents underestimated their child's bystander experience. Similar to cyber aggression among younger children, it may be that restrictive mediation was not effective for parental awareness among younger children because of parents' perceptions that younger children are not exposed to cyberbullying (Monks et al., 2016). Parents should teach their child how to properly report cyberbullying if they witness it so they know their child will act appropriately should they encounter it.

Restrictive mediation of digital media can be challenging for parents. One struggle that many parents face is trying to balance giving their child privacy online while trying to protect them from involvement in cyberbullying (Monks et al., 2016). Children that have superior knowledge of technology can easily bypass or ignore any rules that parents may have implemented that are meant to prevent them from engaging in risky online activities (Monks et al., 2016). One study revealed that $35 \%$ of children admitted to disobeying at least some of their parents' rules (Livingstone et al., 2011). Similarly, McQuade et al. (2009) found that almost $40 \%$ of children said they had no rules. Furthermore, parents often struggle to maintain restrictive mediation strategies they have chosen (Rosen, 2007). The majority of parents in the current study used restrictive mediation and it is likely that they also faced these types of challenges, which may explain why their restrictions were ineffective for their knowledge of their child's cyberbullying experiences. Parents may not be aware of some of these obstacles or how to overcome them, which might have led them to believe that their rules were more effective than they actually were. The current study's results are based mostly on interaction restrictions. This is because the large majority of restrictive mediation practices that parents used were interaction restrictions, while only $4 \%$ used technical restrictions. It is possible that in the current study restrictive mediation did not make parents more aware of cyber aggression and victimization because child participants ignored their parents' rules, which may have rendered the rules ineffective. Perhaps it would have been more difficult for children to bypass the rules if the restrictions were technical, which would physically block children from accessing content. While the current study was unable to determine if this was the case because so few parents implemented technical restrictive mediation, this is something future research should consider investigating.

It is also possible that parents are too busy to explain these rules and talk about them with their child (Warren et al., 2002). Research has shown that children whose parents use restrictive mediation in combination with discussions were less likely to experience cyber victimization (Leduc et al., 2018). Discussions, which are a form of active mediation, have been shown to have similar effects to restrictive mediation for reducing aggressive behaviour (Nathanson, 1999). Given these findings, using restrictive mediation strategies in combination with discussions could be something worth further exploring with regard to parental awareness of cyberbullying experiences, as children may feel more comfortable talking to their parents if parents start the conversation. Overall, the current study suggests that restrictive mediation is effective for parental knowledge of witnessing cyberbullying for adolescents. Future research should consider pairing mediation strategies to determine the most effective form of parental mediation for parental awareness of their child's cyberbullying experience.

\section{Limitations and Future Directions}

The current study had a limited sample of adolescents and future studies should include a larger and more even sample. Furthermore, the group of parents who did not engage in restrictive mediation was very small and this should be taken into consideration when interpreting the results. In addition, given the nature of the design, we were not able to determine if parents set rules as a result of having knowledge of their child's cyberbullying experiences or if parents set rules with the hope of becoming more aware. Future research should consider using longitudinal designs to help establish the temporal relationship. Next, while this study asked parents to report if they used restrictive mediation strategies, it did not ask parents how strictly they enforced these rules. Moreover, while this study used a dyad sample that included a parent and a child, we did not ask children their perceptions of the restrictions that their parents set or if children were respecting them. Future research should incorporate more information about the specific restrictive mediation strategy used (interaction versus technical restrictions) and children's awareness and compliance. Additionally, research should explore what combinations of mediation strategies can improve parental awareness. While this study provided information as to the effectiveness of restrictive mediation on parental awareness, future research can contribute to a more in-depth understanding of what types of restrictive mediation and other forms of parental mediation are more effective in making parents more aware of their child and adolescent's online experience. 


\section{Conclusion}

This study was the first to compare parental awareness of cyberbullying experiences in children and adolescents as a function of restrictive mediation. The current study found that parents thought their child in elementary school engaged in cyber aggression less than they actually did, whereas parents of adolescents in high school thought their adolescent engaged in cyber aggression more than they actually did. The results also suggest that restrictive mediation was more effective for parental awareness of bystander experiences in adolescents. Overall, this study highlights the relationship between parenting methods and parental knowledge of their child's online experiences with bullying. This is useful knowledge for parents as their awareness of cyberbullying could be a step forward towards preventing negative online interactions and experiences in youth.

\section{References}

Ahmad, N., Mokhtar, U. A., Hood, Z., Tiun, S., \& Jambari, D. I. (2019). Parental awareness on cyber threats using social media. Jurnal Komunikasi: Malaysian Journal of Communication, 35(2), 485-498. https://doi.org/10.17576/JKMJC-20193502-29

Anderson, M. (2018, September 27). A majority of teens have experienced some form of cyberbullying. Pew Researcher Center: Internet \& Technology. https://www.pewinternet.org/2018/09/27/a-majority-of-teens-have-experienced-someform-of-cyberbullying/

Ang, R. P. (2015). Adolescent cyberbullying: A review of characteristics, prevention and intervention strategies. Aggression and Violent Behavior, 25(Part A), 35-42. https://doi.org/10.1016/j.avb.2015.07.011

Ang, R. P., Chong, W. H., Chye, S., \& Huan, V. S. (2012). Loneliness and generalized problematic Internet use: Parents' perceived knowledge of adolescents' online activities as a moderator. Computers in Human Behavior, 28(4), 1342-1347. https://doi.org/10.1016/j.chb.2012.02.019

Barlett, C. P., \& Fennel, M. (2018). Examining the relation between parental ignorance and youths' cyberbullying perpetration. Psychology of Popular Media Culture, 7(4), 547-560. https://doi.org/10.1037/ppm0000139

Belsey, B. (2019, March 24). Cyberbullying: An emerging threat to the "always on" generation. Bill Belsey. http://www.billbelsey.com/?p=1827

Bybee, C. R., Robinson, D., \& Turow, J. (1982). Determinants of parental guidance of children's television viewing for a special subgroup: Mass media scholars. Journal of Broadcasting, 26(3), 697-710.

https://doi.org/10.1080/08838158209364038

Byrne, S., Katz, S. J., Lee, T., Linz, D., \& Mcllrath, M. (2014). Peers, predators, and porn: Predicting parental underestimation of children's risky online experiences. Journal of Computer-Mediated Communication, 19(2), $215-231$. https://doi.org/10.1111/jcc4.12040

Cerna, A., Machackova, H., \& Dedkova, L. (2016). Whom to trust: The role of mediation and perceived harm in support seeking by cyberbullying victims. Children \& Society, 30(4), 265-277. https://doi.org/10.1111/chso.12136

Chang, F.-C., Chiu, C.-H., Miao, N.-F., Chen, P.-H., Lee, C.-M., Chiang, J.-T., \& Pan, Y.-C. (2015). The relationship between parental mediation and Internet addiction among adolescents, and the association with cyberbullying and depression. Comprehensive Psychiatry, 57, 21-28. https://doi.org/10.1016/j.comppsych.2014.11.013

Chng, G. S., Liau, A., Khoo, A., \& Li, D. (2014). Parental mediation and cyberbullying - A longitudinal study. Annual Review of CyberTherapy and Telemedicine, 12, 98-102. http://www.arctt.info/volume-12-summer-2014

Cho, C.-H., \& Cheon, H. J. (2005). Children's exposure to negative Internet content: Effects of family context. Journal of Broadcasting \& Electronic Media, 49(4), 488-509. https://doi.org/10.1207/s15506878jobem4904_8 
Clark, L. S. (2011). Parental mediation theory for the digital age. Communication Theory, 21(4), 323-343.

https://doi.org/10.1111/j.1468-2885.2011.01391.x

Daneels, R., \& Vanwynsberghe, H. (2017). Mediating social media use: Connecting parents' mediation strategies and social media literacy. Cyberpsychology: Journal of Psychosocial Research on Cyberspace, 11(3), Article 5.

http://dx.doi.org/10.5817/CP2017-3-5

Dehue, F., Bolman, C., \& Völlink, T. (2008). Cyberbullying: Youngsters' experiences and parental perception. CyberPsychology \& Behavior, 11(2), 217-223. https://doi.org/10.1089/cpb.2007.0008

Dorr, A., Kovaric, P., \& Doubleday, C. (1989). Parent-child coviewing of television. Journal of Broadcasting \& Electronic Media, 33(1), 35-51. https://doi.org/10.1080/08838158909364060

Ho, S. S., Chen, L., \& Ng, A. P. Y. (2017). Comparing cyberbullying perpetration on social media between primary and secondary school students. Computers \& Education, 109, 74-84. https://doi.org/10.1016/j.compedu.2017.02.004

Ipsos. (2013). Bullies taking to social networking as teens become more mobile. https://www.ipsos.com/en-ca/bulliestaking-social-networking-teens-become-more-mobile

Katz, S. J., Lee, T., \& Byrne, S. (2015). Predicting parent-child differences in perceptions of how children use the Internet for help with homework, identity development, and health Information. Journal of Broadcasting \& Electronic Media, 59(4), 574-602. https://doi.org/10.1080/08838151.2015.1093479

Leduc, K., Caivano, O., Van De Loo, E., \& Talwar, V. (2018, May 3-4). Does it make a difference? The effect of parents' rules and discussions on children's exposure to cyberbullying [Poster presentation]. Development 2018: A Canadian Conference on Developmental Psychology, St. Catharines, Ontario, Canada.

Lee, S.-J. (2012). Parental restrictive mediation of children's internet use: Effective for what and for whom? New Media \& Society, 15(4), 466-481. https://doi.org/10.1177/1461444812452412

Livingstone, S., \& Bober, M. (2004). UK children go online: surveying the experiences of young people and their parents. LSE Research Online. http://eprints.Ise.ac.uk/395/

Livingstone, S., Haddon, L., Görzig, A., \& Ólafsson, K. (2011). Risks and safety on the Internet: The perspective of European children: Full findings and policy implications from the EU Kids Online survey of 9-16 year olds and their parents in 25 countries. EU Kids Online. http://eprints.Ise.ac.uk/33731/

Livingstone, S., \& Helsper, E. J. (2008). Parental mediation of children's internet use. Journal of Broadcasting \& Electronic Media, 52(4), 581-599. https://doi.org/10.1080/08838150802437396

Mascheroni, G. (2014). Parenting the mobile Internet in Italian households: Parents' and children's discourses. Journal of Children and Media, 8(4), 440-456. https://doi.org/10.1080/17482798.2013.830978

Mascheroni, G., \& Cuman, A. (2014). Net Children Go Mobile: Final report (Deliverables D6.4 \& D5.2). Educatt. http://netchildrengomobile.eu/ncgm/wp-content/uploads/2013/07/NCGM_FinalReport_Country_DEF.pdf

McQuade, S. C., Colt, J. P., \& Meyer, N. B. (2009). Cyberbullying: Protecting kids and adults from online bullies. Praeger Publishers.

Menesini, E., Nocentini, A., \& Calussi, P. (2011). The measurement of cyberbullying: Dimensional structure and relative item severity and discrimination. Cyberpsychology, Behavior, and Social Networking, 14(5), 267-274.

https://doi.org/10.1089/cyber.2010.0002

Mesch, G. S. (2009). Parental mediation, online activities, and cyberbullying. CyberPsychology \& Behavior, 12(4), 387393. https://doi.org/10.1089/cpb.2009.0068 
Monks, C. P., Mahdavi, J., \& Rix, K. (2016). The emergence of cyberbullying in childhood: Parent and teacher perspectives. Psicología Educativa, 22(1), 39-48. https://doi.org/10.1016/j.pse.2016.02.002

Nathanson, A. I. (1999). Identifying and explaining the relationship between parental mediation and children's aggression. Communication Research, 26(2), 124-143. https://doi.org/10.1177/009365099026002002

Nathanson, A. I. (2002). The unintended effects of parental mediation of television on adolescents. Media Psychology, 4(3), 207-230. https://doi.org/10.1207/S1532785XMEP0403_01

Nathanson, A. I., Eveland, W. P. Jr., Park, H.-S., \& Paul, B. (2002). Perceived media influence and efficacy as predictors of caregivers' protective behaviors. Journal of Broadcasting \& Electronic Media, 46(3), 385-410.

https://doi.org/10.1207/s15506878jobem4603_5

Navarro, R., Serna, C., Martínez, V., \& Ruiz-Oliva, R. (2013). The role of Internet use and parental mediation on cyberbullying victimization among Spanish children from rural public schools. European Journal of Psychology of Education, 28(3), 725-745. https://doi.org/10.1007/s10212-012-0137-2

Nikken, P., \& Jansz, J. (2014). Developing scales to measure parental mediation of young children's internet use. Learning, Media and Technology, 39(2), 250-266. https://doi.org/10.1080/17439884.2013.782038

PREVNet. (2014). Cyberbullying and how it is affecting Canadian youth. https://www.prevnet.ca/research/bullyingstatistics/cyberbullying

Rosen, L. D. (2007). Me, MySpace, and I: Parenting the Net Generation. Palgrave Macmillan.

Sasson, H., \& Mesch, G. (2014). Parental mediation, peer norms and risky online behavior among adolescents. Computers in Human Behavior, 33, 32-38. https://doi.org/10.1016/j.chb.2013.12.025

Smith, P. K., Mahdavi, J., Carvalho, M., Fisher, S., Russell, S., \& Tippett, N. (2008). Cyberbullying: Its nature and impact in secondary school pupils. Journal of Child Psychology and Psychiatry, 49(4), 376-385. https://doi.org/10.1111/j.14697610.2007.01846.x

Spears, G., Seydegart, K., \& Zulinov, P. (2005). Young Canadians in a wired world: Phase II: Student survey. Media Awareness Network. https://mediasmarts.ca/sites/mediasmarts/files/pdfs/publication-report/full/YCWWII-studentsurvey.pdf

Symons, K., Ponnet, K., Emmery, K., Walrave, M., \& Heirman, W. (2016). Parental knowledge of adolescents' online content and contact risks. Journal of Youth and Adolescence, 46(2), 401-416. https://doi.org/10.1007/s10964-016-05997

Symons, K., Ponnet, K., Emmery, K., Walrave, M., \& Heirman, W. (2017). A factorial validation of parental mediation strategies with regard to internet use. Psychologica Belgica, 57(2), 93-111. https://doi.org/10.5334/pb.372

Van den Bulck, J., \& Van den Bergh, B. (2000). The influence of perceived parental guidance patterns on children's media use: Gender differences and media displacement. Journal of Broadcasting \& Electronic Media, 44(3), 329-348. https://doi.org/10.1207/s15506878jobem4403_1

van Kruistum, C., \& van Steensel, R. (2017). The tacit dimension of parental mediation. Cyberpsychology: Journal of Psychosocial Research on Cyberspace, 11(3), Article 3. http://dx.doi.org/10.5817/CP2017-3-3

Wang, R., Bianchi, S. M., \& Raley, S. B. (2005). Teenagers' Internet use and family rules: A research note. Journal of Marriage and Family, 67(5), 1249-1258. https://doi.org/10.1111/j.1741-3737.2005.00214.x

Warren, R., Gerke, P., \& Kelly, M. A. (2002). Is there enough time on the clock? Parental involvement and mediation of children's television viewing. Journal of Broadcasting \& Electronic Media, 46(1), 87-111.

https://doi.org/10.1207/s15506878jobem4601_6 
Weintraub Austin, E. (1993). Exploring the effects of active parental mediation of television content. Journal of Broadcasting \& Electronic Media, 37(2), 147-158. https://doi.org/10.1080/08838159309364212

Wong, Y. C. (2010). Cyber-parenting: Internet benefits, risks and parenting issues. Journal of Technology in Human Services, 28(4), 252-273. https://doi.org/10.1080/15228835.2011.562629

Wright, M. F. (2016). The buffering effect of parental mediation in the relationship between adolescents' cyberbullying victimisation and adjustment difficulties. Child Abuse Review, 25(5), 345-358. https://doi.org/10.1002/car.2448

Wright, M. F. (2017). Parental mediation, cyberbullying, and cybertrolling: The role of gender. Computers in Human Behavior, 71, 189-195. https://doi.org/10.1016/j.chb.2017.01.059

Zaman, B., Nouwen, M., Vanattenhoven, J., de Ferrerre, E., \& Van Looy, J. (2016). A qualitative inquiry into the contextualized parental mediation practices of young children's digital media use at home. Journal of Broadcasting \& Electronic Media, 60(1), 1-22. https://doi.org/10.1080/08838151.2015.1127240

Zeedyk, M. S., Gallacher, J., Henderson, M., Hope, G., Husband, B., \& Lindsay, K. (2003). Negotiating the transition from primary to secondary school: Perceptions of pupils, parents and teachers. School Psychology International, 24(1), 67-79. https://doi.org/10.1177/0143034303024001010

\section{Correspondence to:}

Oksana Caivano

McGill University

3700 McTavish Street

Montreal, H3A 1 Y2

Canada

Email: oksana.caivano(at)mail.mcgill.ca

Editorial record: First submission received on February 1, 2019. Revisions received on September 2, 2019, January 13, 2020 and January 30, 2020. Accepted for publication on January 30, 2020.

Editor in charge: Michel Walrave

\section{About Authors}

Oksana Caivano, M.A., is a doctoral student in Human Development at McGill University. Her research focuses on gossiping and peer relations among children and adolescents.

Karissa Leduc, M.A., is a doctoral candidate in Human Development at McGill University. Her research focuses on children's and adolescents' moral development and behaviours on digital media.

Victoria Talwar, Ph.D., is Professor and Canada Research Chair (II) in the Department of Educational and Counselling Psychology at McGill University. Her research focuses on children's moral development and social adjustment in applied settings. 